\title{
In vitro biological activity of bovine milk ribonuclease-4
}

\author{
R. DI LIDDO ${ }^{1}$, D. DALZOPPO ${ }^{1}$, S. BAIGUERA ${ }^{1}$, M.T. CONCONI ${ }^{1}$, \\ M. DETTIN ${ }^{2}$, P.P. PARNIGOTTO ${ }^{1}$ and C. GRANDI ${ }^{1}$ \\ Departments of ${ }^{1}$ Pharmaceutical Sciences, and ${ }^{2}$ Chemical Process Engineering, University of Padova, I-35128 Padova, Italy
}

Received September 9, 2009; Accepted October 27, 2009

DOI: $10.3892 / \mathrm{mmr} 000000229$

\begin{abstract}
Several members of the ribonuclease superfamily possess a variety of interesting biological properties, including ribonucleolytic, angiogenic, antiproliferative, cytotoxic, embryotoxic, aspermatogenic and antitumoral activity. In this study, we report the purification from bovine milk of a protein with structural and enzymatic properties very similar to those of ribonuclease-4 (RNase-4), which is normally present in the liver and lungs, and examined its functional properties, biological activity and cytotoxic effects. RNase-4, at physiological concentrations, had a positive effect on the vitality and proliferation of human umbilical vein endothelial cells. Moreover, it induced an increase in cellular migration and the formation of in vitro capillary-like structures. We also evaluated the effect of RNase-4 in vitro on human breast, colorectal and cervical carcinoma cell lines. The protein was revealed to have a cytotoxic effect similar to that of RNase-A. We suggest that the positive effects of RNase- 4 on normal cells were due to its particularly close interaction with RNase inhibitor, while good conformational stability and resistance to proteolytic degradation potentially favour ribonuclease cytotoxicity.
\end{abstract}

\section{Introduction}

Ribonucleases (RNases) play a critical role in numerous biological processes. Most are not just simple digestive enzymes; they also exhibit biological functions: eosinophil-derived neurotoxin and eosinophil cationic proteins exert neurotoxicity and show antiparasitic activity (1), bovine seminal ribonuclease induces apoptosis in carcinoma cell lines (2), and onconase, extracted from Rana pipiens, is cytotoxic and cytostatic on several tumor lines and is currently in Phase III clinical trials for the treatment of malignant mesothelioma (3). The specific ability of RNases to cleave ribonucleic acid also enables them to act as immunotoxins capable of inducing cellular death.

Ribonuclease-4 (RNase-4) has been isolated from various animals and appears in the literature under several names. It

Correspondence to: Professor C. Grandi, Department of Pharmaceutical Sciences, Via Marzolo 5, Padova I-35121, Italy E-mail: claudio.grandi@unipd.it

Key words: ribonuclease, cell proliferation, angiogenesis, cytotoxicity, carcinoma cell lines, human umbilical vein endothelial cells is a ubiquitous enzyme and is present in the highest amounts in the liver and lungs (4). A salient feature of RNase-4, which distinguishes it from other RNases, is its high interspecies similarity (90\%), which strongly suggests that it performs a more specialized function than simply digesting or "cleaning up' RNA (5). It was first isolated from bovine tissues in 1987 , at which time it was called RNase BL4 (6). Since then, it has been relatively poorly studied; at present, there are no reports in the literature on its biological activity or possible cytotoxic properties.

Bovine pancreatic ribonuclease-A (RNase-A) is the most frequently studied member of the RNase family, and has been used as a model to analyze protein structure and function $(5,6)$.

The aims of this study were to analyze the molecular structure and enzymatic properties of bovine milk protein and identify it as RNase-4, and then to evaluate, in comparison with RNase-A, its biological properties on human umbilical vein endothelial cells (HUVECs) and its cytotoxic effects on breast, colorectal and cervical carcinoma cell lines.

The identification of RNase- 4 in bovine milk would enable a more accessible source of easily obtained and purified functional RNase-4.

\section{Materials and methods}

Protein purification. The protein was isolated from dairy bovine milk following the procedure described by $\mathrm{Ye}$ et al (7). Briefly, milk was acidified ( $\mathrm{pH} 4.3)$ with $\mathrm{HCl}(3 \mathrm{M})$ and then filtered with filter paper (Whatman, Brentford, UK). The globulin fraction together with the protein was precipitated from acid whey with ammonium sulfate $(3.6 \mathrm{M}$ final concentration) and recovered by centrifugation at 4,500 $\mathrm{rpm}$ for $30 \mathrm{~min}$ at $8^{\circ} \mathrm{C}$. After dialysis against sodium phosfate buffer (10 mM, pH 7.5), first ion exchange chromatography (IEC) was carried out on CM-Sepharose FF (Amersham Biosciences, Piscataway, NJ, USA) at $\mathrm{pH}$ 7.7, followed by high-resolution IEC on a Mono-S column. The latter chromatographic step allowed the recovery of purified protein, which was further chromatographed by RP-HPLC on a Vydac C4 column (The Separation Group, Hesperia, CA, USA). Final protein purity was checked by SDS-PAGE and identification was made by ESI-TOF mass spectrometry on a Mariner ${ }^{\mathrm{TM}}$ spectrometer (Perseptive Biosystems, Framingham, MA, USA). Commercial RNase-A was purchased from Sigma and further purified by RP-HPLC on a Vydac C4 column. 
Spectroscopic measurements. Protein concentration was determined by ultraviolet (UV) absorption measurements at $280 \mathrm{~nm}$ on a double-beam Model Lambda-2 spectrophotometer from Perkin-Elmer (Norwalk, CT, USA). Absorption coefficients of $1 \mathrm{mg} / \mathrm{ml}$ protein solutions at $280 \mathrm{~nm}$ were calculated according to Gill (9) and taken as 0.59 and 0.72 for RNase-A and RNase-4, respectively. Circular dichroism (CD) spectra were recorded on a Jasco (Tokyo, Japan) Model J-810 spectropolarimeter, equipped with a thermostated cell holder and a NesLab (Newington, NH, USA) Model RTE-110 water circulating bath. The instrument was calibrated with $d$-(+)-10-camphorsulfonic acid (10). Far- and near-UV CD spectra were recorded at protein concentrations ranging from 0.1 to $1 \mathrm{mg} / \mathrm{ml}$ at $25^{\circ} \mathrm{C}$ in sodium phosfate $(10 \mathrm{mM})$ and $\mathrm{NaCl}(150 \mathrm{mM})$ buffer ( $\mathrm{pH}$ 6.5), with 1- or 10-mm path length quartz cells in the far- and near-UV regions, respectively. Scan velocity was $20 \mathrm{~nm} / \mathrm{min}$, and four scans, with a time constant of $4 \mathrm{sec}$, were averaged.

Enzyme kinetic measurements. The ribonucleolytic activity of the RNase-4 towards $\mathrm{CpG}$ or UpG nucleotides was measured by HPLC quantification of starting substrates with respect to ribonucleolytic products $(\mathrm{CpG}$ vs. $\mathrm{Cp}$ and $\mathrm{G}$ or $\mathrm{UpG}$ vs. $\mathrm{Up}$ and $\mathrm{G}$, respectively). An incubation mixture of $50 \mu \mathrm{l}$ typically contained $0.1 \mu \mathrm{M}$ enzyme, $\mathrm{CpG}$ or $\mathrm{UpG}$ at various concentrations (5-100 $\mu \mathrm{M})$ and buffer composed of MES (33 mM, pH 6.0) and $\mathrm{NaCl}(33 \mathrm{mM})$. After incubation at $37^{\circ} \mathrm{C}$, the reaction was stopped with $30 \mu \mathrm{l}$ of TFA $(0.1 \%)$ and an aliquot was injected into a Vydac C18 analytical column. In order to measure initial velocities, incubation times were adjusted to have only $5-10 \%$ substrate hydrolysis. The isocratic eluent was water/acetonitrile $(97.5 / 2.5)$ containing TFA $(0.05 \%)$, and the flow rate was $1 \mathrm{ml} / \mathrm{min}$. The detection wavelength was $260 \mathrm{~nm}$. The specificity constant $\mathrm{k}_{\mathrm{cat}} / \mathrm{K}_{\mathrm{m}}$ was estimated assuming that the substrate concentration was below $\mathrm{K}_{\mathrm{m}}$, product inhibition was negligible and the reaction was first-order with respect to the substrate.

Cell cultures. HUVECs isolated from fresh umbilical cords as previously described (11) were maintained in culture $\left(37^{\circ} \mathrm{C}\right.$, $\left.5 \% \mathrm{CO}_{2}\right)$ on fibronectin (Sigma) $\left(1 \mu \mathrm{g} / \mathrm{cm}^{2}\right)$-coated dishes (Becton Dickinson, Franklin Lakes, NJ, USA) in endothelial cell growth medium MV2 (PromoCell, Heidelberg, Germany) supplemented with foetal calf serum (FCS) $(5 \%)$, epidermal growth factor $(5 \mathrm{ng} / \mathrm{ml})$, hydrocortison $(0.2 \mu \mathrm{g} / \mathrm{ml})$, vascular endothelial growth factor (VEGF) $(0.5 \mathrm{ng} / \mathrm{ml})$, basic fibroblast growth factor (bFGF) (10 ng/ml), R3 IGF-1 (20 ng/ml) and ascorbic acid $(1 \mu \mathrm{g} / \mathrm{ml})$. Cells between passages 2 and 5 were used for all experiments. The MCF-7 human breast and HT-29 human colorectal carcinoma cell lines were obtained from the American type Culture Collection (Rockville, MD, USA). A431 human cervical carcinoma was kindly provided by Professor Zunino (Division of Experimental Oncology B, Istituto Superiore dei Tumori, Milan, Italy). Cell lines were maintained in the logarithmic phase at $37^{\circ} \mathrm{C}$ in a $5 \% \mathrm{CO}_{2}$ atmosphere in RPMI-1640 medium (Euroclone, Celbio, Milan, Italy) supplemented with FCS (10\%) (Biochrom-Seromed $\mathrm{GmbH}$, Berlin, Germany), HEPES buffer $(25 \mathrm{mM})$, penicillin (50 units $\left.\mathrm{ml}^{-1}\right)$ and streptomycin $\left(50 \mu \mathrm{g} \mathrm{ml}^{-1}\right)$.
Cell vitality assay. Cell vitality was monitored by the colorimetric MTS assay 3-(4,5-dimethylthiazol-2-yl)-5-(3carboxymethoxyphenyl)-2-(4-sulfophenyl)-2H-tetrazolium, inner salt) (CellTiter 96 Aqueous Assay; Promega, Madison, WI, USA). Metabolically active cells react with tetrazolium salt in the MTS reagent to produce a soluble formazan dye observable at a wavelength of $490 \mathrm{~nm}$. HUVECs were seeded $\left(1.5 \times 10^{4}\right.$ cells $\left./ \mathrm{cm}^{2}\right)$ in a 96 -well plate (Becton Dickinson) and cultured for $24 \mathrm{~h}$ at $37^{\circ} \mathrm{C}$ in endothelial growth medium. After incubation, the medium was replaced with $\mathrm{MV}$ basal medium and bFGF (2.5 ng/ml) (Sigma). RNase-A or RNase-4 $\left(10^{-8} \mathrm{M}\right)$ was added, and cells were incubated at $37^{\circ} \mathrm{C}$. After $24 \mathrm{~h}$, the medium was replaced with a fresh one containing MTS dye (20\%), and the dishes were incubated for $2 \mathrm{~h}$. Absorbance was determined at $490 \mathrm{~nm}$ with an ELISA Ultra Microplate Reader (Bio-tek Instruments, Winooski, VT, USA). Results are expressed as the percent change from control values.

Cell proliferation assay. The HUVEC proliferation rate was measured by assaying the incorporation of BrdU into the DNA of proliferating cells by means of the Roche Cell Proliferation Kit (Roche Molecular Diagnostics, Pleasanton, CA, USA). Cells were seeded $\left(1.5 \times 10^{4}\right.$ cells $\left./ \mathrm{cm}^{2}\right)$ in a 96 -well plate (Becton Dickinson) and cultured for $24 \mathrm{~h}$ at $37^{\circ} \mathrm{C}$ in endothelial growth medium. After incubation, the medium was replaced with MV basal medium and bFGF (2.5 ng/ $\mathrm{ml}$ ) (Sigma). RNase-A or RNase-4 $\left(10^{-8} \mathrm{M}\right)$ was added, and cells were incubated at $37^{\circ} \mathrm{C}$. BrdU $(10 \mu \mathrm{M})$ was added to the culture medium and the assay was performed after 24 h. HUVECs were harvested, their DNA was extracted, and incorporated $\mathrm{BrdU}$ was detected by an immunoassay with anti-BrdU-POD conjugated antibody. Absorbance was determined on an ELISA reader (ELx808, BioTek) at $450 \mathrm{~nm}$. Two controls were performed: i) blank, unspecific binding of BrdU and anti-BrdU-POD conjugate to the polystyrene dish, and ii) background, unspecific binding of anti-BrdU-POD conjugate to HUVECs in the absence of BrdU. Each sample was assayed in triplicate. Results are expressed as the percent change from control values.

In vitro angiogenesis assay. A morphogenic assay was performed by plating HUVECs on Matrigel(Becton Dickinson). Briefly, Matrigel was thawed on ice overnight, spread evenly over each well $(50 \mu \mathrm{l})$ of a 24 -well plate, and allowed to gel for $30 \mathrm{~min}$ at $37^{\circ} \mathrm{C}$. HUVECs were seeded $\left(2.5 \times 10^{4}\right.$ cells/ $\mathrm{cm}^{2}$ ) and cultured in MV basal medium containing or not containing VEGF (10 ng/ml), RNase-A or RNase-4 (10-8 M). After $24 \mathrm{~h}$, cultures were fixed with glutaraldehyde (2\%) and photographed (5 fields/well; the 4 quadrants and the central field) at a magnification of x100. Phase contrast images were recorded on a digital camera (PS-S70) (Canon, Lake Success, NY, USA). Image analysis was carried out with Qwin image analysis software (Leica Imaging System) as previously described (12), and dimensional (percent area covered by HUVECs and total length of HUVEC network per field) and topological (number of meshes and branching points per field) parameters were estimated. Assays was performed in triplicate. Results are expressed as the percent difference between treated and control samples. 
A

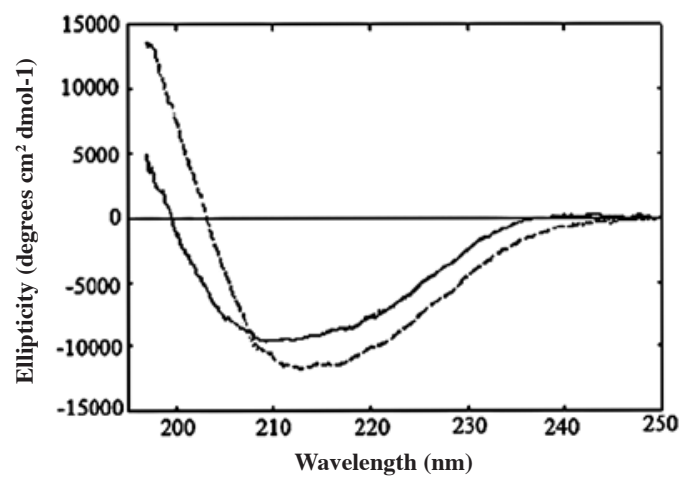

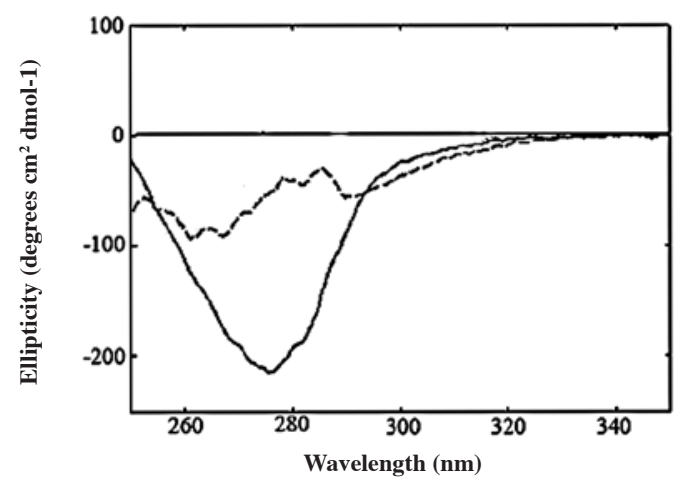

Figure 1. CD spectra of RNase-A (---) and RNase-4 (-) observed in (A) far- and (B) near-UV regions. Spectra were recorded at $25^{\circ} \mathrm{C}$ in 10 mM sodium phosfate buffer $\mathrm{pH} 6.5$ containing $150 \mathrm{mM} \mathrm{NaCl}$, with 1- or 10-mm path length quartz cells in far- and near-UV regions, respectively. Protein concentrations were 0.1 and $1 \mathrm{mg} / \mathrm{ml}$ in far- and near-UV regions, respectively.

Cell migration assay. Chemotaxis experiments were performed with the Boyden chamber technique (24-well chemotaxis chamber) with $8-\mu \mathrm{m}$ pore size polycarbonate membranes (Costar, Acton, MA, USA). HUVECs were seeded $\left(7.4 \times 10^{4}\right.$ cells/insert) into the upper surface of the membrane insert, preconditioned with fibronectin $(10 \mu \mathrm{g} / \mathrm{ml})$ and cultured in MV basal medium containing FCS (1\%). After $2 \mathrm{~h}$, RNase-A or RNase-4 $\left(10^{-8} \mathrm{M}\right)$ were placed in the lower compartment of the chamber, while FCS (10\%) was added to the MV medium in the controls. After $22 \mathrm{~h}$, the upper surface of the filter was gently scraped to remove non-migrated cells. Filters were fixed with iced methanol and stained with 4',6diamidino-2-phenylindole (DAPI) (Vector Laboratories Ltd., Peterborough, UK). Experiments were performed in triplicate and the number of cells present in 5 fields/well was counted at magnification of $\mathrm{x} 40$ on a Laborlux-S microscope (Leitz, Wetzlar, Germany). Results are expressed as the percent difference between treated and control samples.

Cytotoxicity assay. The growth inhibitory effect on the tumor cell lines was evaluated by means of the MTT (3-(4,5dimethylthiazol-2-yl)-2,5-diphenyltetrazolium bromide) saline solution assay (13). Briefly, cells $\left(2.5 \times 10^{4} \mathrm{cells} / \mathrm{cm}^{2}\right.$ for MCF7 and $1.5 \times 10^{4}$ cells $/ \mathrm{cm}^{2}$ for HT29 and A431) were seeded in 96-well microplates in growth medium. After $12 \mathrm{~h}$, the cells were treated with increasing concentrations of RNase-A or RNase-4. After $72 \mathrm{~h}$, MTT dye was added to the culture medium $(5 \mathrm{mg} / \mathrm{ml})$ and, after $5 \mathrm{~h}, 100 \mu \mathrm{l}$ of a sodium dodecylsulfate solution in $\mathrm{HCl}(0.01 \mathrm{M})$ was added. After overnight incubation, the absorbance of each well was detected by a microplate reader (Biorad 680; Biorad, Milan, Italy) at $570 \mathrm{~nm}$. Mean absorbance for each dose was expressed as a percentage of absorbance with respect to the untreated control well and plotted vs. drug concentration. $\mathrm{IC}_{50}$ values represent the drug concentrations that reduced the mean absorbance at $570 \mathrm{~nm}$ to $50 \%$ of that of the untreated control wells.

Statistical analysis. Data are expressed as the mean \pm standard deviation of four separate experiments. Statistical analysis was performed by ANOVA followed by the Student-NewmanKeuls t-test as a post-hoc test (SPSS 12.0; SPSS Inc, USA). The level of significance was set at $\mathrm{p}<0.05$.
Table I. Specificity constants for RNase-4.

\begin{tabular}{lcc}
\hline Enzyme & Substrate & $\mathrm{k}_{\mathrm{cat}} / \mathrm{K}_{\mathrm{m}}$ at $37^{\circ} \mathrm{C}, \mathrm{M}^{-1} \mathrm{sec}^{-1}$ \\
\hline RNase-4 & $\mathrm{CpG}$ & 10.1 \\
RNase-4 & $\mathrm{UpG}$ & 1770 \\
\hline
\end{tabular}

Measurements were made at $37^{\circ} \mathrm{C}$ in buffer composed of MES (33 mM, pH 6.0) and $\mathrm{NaCl}(33 \mathrm{mM})$.

\section{Results and Discussion}

Protein purification was achieved by means of various chromatographic techniques, such as ion exchange and HPLC reverse phase chromatography, which easily separated the protein from other proteic milk materials and allowed protein purification at a very high level. Mass spectrometry also analyzed protein tryptic fragments and identified the protein as RNase-4. In order to confirm the secondary structure of bovine milk RNase-4, far- and near-UV spectra were measured in comparison with RNase-A. Far-UV CD spectra (Fig. 1A) revealed similar shape and intensity bands between the two ribonucleases; secondary structure elements, in particular the $\alpha$-helix, were present in comparable amounts in the two proteins, confirming the data in the literature (4). However, near-UV CD spectra highlighted subtle differences in the tertiary structures of the two proteins (Fig. 1B). Bovine milk RNase-4 kinetic properties in cleaving simple dinucleotide substrates, such as $\mathrm{CpG}$ and $\mathrm{UpG}$, were measured at $\mathrm{pH} 6.0$ (Table I). Our results showed that the specificity of UpG was higher than that of $\mathrm{CpG}$, confirming the nature of RNase-4. The singular specificity of this RNase has been reported to have a marked preference for uridine compared with cytidine, in contrast to the more general pyrimidine specificity of other ribonucleases such as RNase-1, -2, -3 and angiogenin (5). The kinetic constant obtained was lower than that reported in the literature for human and porcine RNase-4 (4). In our opinion, this mismatch is due to the difference in dinucleotide substrates used (UpA and CpA, instead of UpG and CpG).

Collectively, our data confirm the isolation and purification of a functional RNase-4 from bovine milk. 


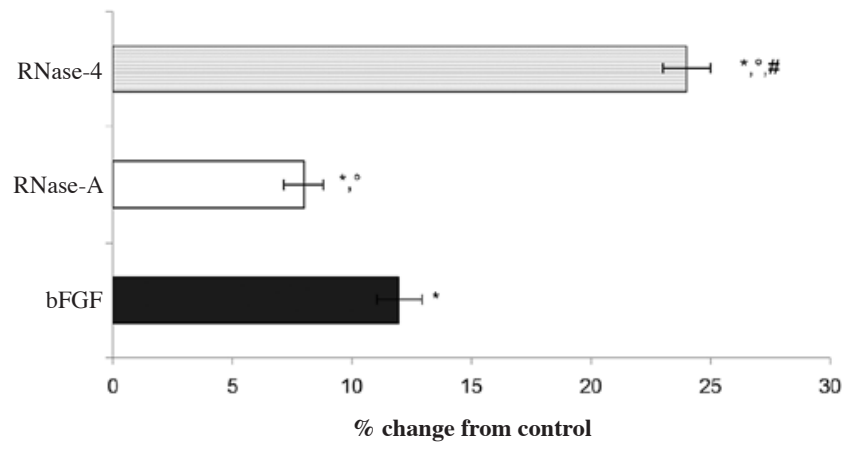

Figure 2. HUVEC vitality evaluated by the MTS assay after $24 \mathrm{~h}$ of treatment ("p $<0.05$ with respect to controls; ${ }^{\circ} \mathrm{p}<0.05$ with respect to bFGF treatment; ${ }^{\#} \mathrm{p}<0.05$ with respect to RNase-A treatment).

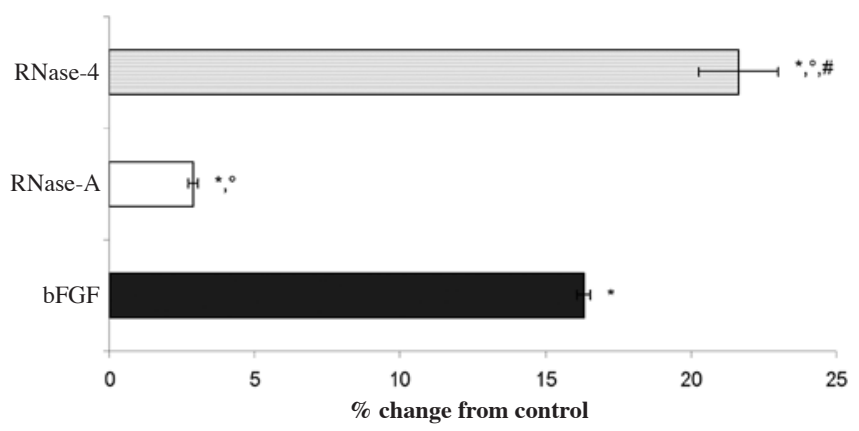

Figure 3. HUVEC proliferation evaluated using the BrdU incorporation assay after $24 \mathrm{~h}$ of treatment $\left(* \mathrm{p}<0.05\right.$ with respect to controls; ${ }^{\circ} \mathrm{p}<0.05$ with respect to $b F G F$ treatment; ${ }^{*} \mathrm{p}<0.05$ with respect to RNase-A treatment).

In order to evaluate RNase-4 biological activity, we tested its effect on HUVEC vitality, proliferation and in vitro angiogenesis at a physiological concentration $\left(10^{-8} \mathrm{M}\right)$. As shown in Fig. 2, the MTS assay revealed that all treatments induced a significant $(p<0.05)$ increase in HUVEC vitality with respect to the controls. In particular, RNase-4 treatment induced an enhanced vitality effect. A BrdU incorporation assay was performed to evaluate the effect of proteins on HUVEC proliferation (Fig. 3). As in the vitality assay, the treatments induced a significant $(\mathrm{p}<0.05)$ increase in the proliferation rate with respect to the controls, with RNase-4 showing a greater increase. As shown in Fig. 4, RNase-4 induced a significant $(p<0.05)$ migration effect through the Boyden chamber with respect to RNase-A, which, in contrast, induced a $20 \%$ inhibition compared to the controls. Normally, HUVECs plated on Matrigel and supplemented with angiogenic factors form a 3D network of capillary-like structures. As shown in Fig. 5, control cultures exhibited rounded, isolated cells, whereas treatment with VEGF, RNase-4 and RNase-A promoted HUVEC spreading and alignment to form branching anastomosing tubes, which gave rise within $18 \mathrm{~h}$ to a mesh of capillarylike structures. Image analysis confirmed these observations, showing that all treatments uploaded dimensional parameters (percent area covered by HUVECs and total length of network per field) and the number of branching points per field of the capillary-like network (Fig. 6). In particular, RNase-4 induced a significantly $(\mathrm{p}<0.05)$ higher angiogenic effect than RNase-A.

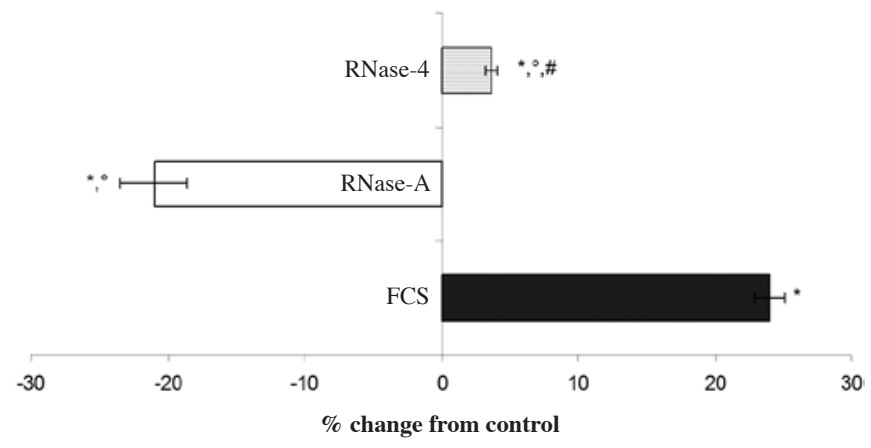

Figure 4. HUVEC migration calculated as the mean number of cells (\%) migrating in the presence of factors with respect to the number of cells migrating in absence of factors $\left({ }^{*} \mathrm{p}<0.05\right.$ with respect to controls; ${ }^{\circ} \mathrm{p}<0.05$ with respect to FCS treatment; ${ }^{\#} \mathrm{p}<0.05$ with respect to RNase-A treatment).
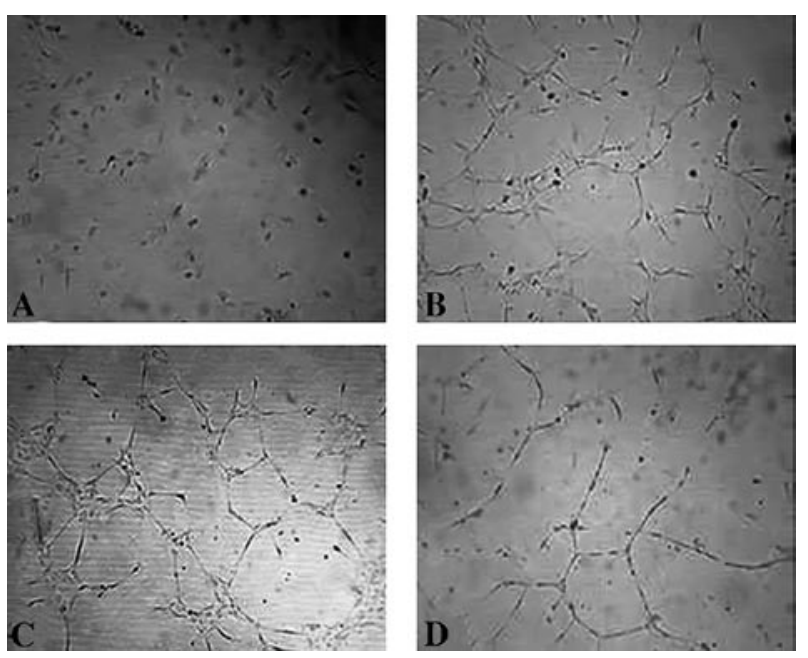

Figure 5. Phase-contrast micrographs illustrating the arrangement of HUVECs in a mesh of capillary-like tubules after being cultured on (A) Matrigel for $24 \mathrm{~h}$, and after treatment with (B) VEGF, (C) RNase-A and (D) RNase-4.

We found that RNase-4 induced not only cellular vitality and proliferation, but also cell migration, one of the first steps essential for angiogenesis, and the formation of capillary-like structures on Matrigel.

It has already been demonstrated that bovine RNase-A has weak toxic properties (10). As there are no data in the literature regarding similar RNase-4 effects, we evaluated the in vitro cytotoxicity of RNase-4 on human breast, colorectal and cervical carcinoma cell lines. Fig. 7 shows the dose response profiles obtained after $72 \mathrm{~h}$ of drug treatment. The data indicated that MCF-7 and HT-29 cells are markedly more sensitive than A431 cells to ribonuclease treatment, and RNase-4 was revealed to have a cytotoxic effect similar to that of RNase-A.

We hypothesized that the positive effects of RNase-4 on normal cells were due to its particularly close interaction with RNase inhibitor (RI). All mammalian RNases interact with RI present in the cytoplasm of virtually all mammalian cells, and it has been reported that the binding of RNase- 4 with human RI is at least 9-fold closer than that of RNase-A (15). Considering the effects of ribonuclease on tumor cell lines, 


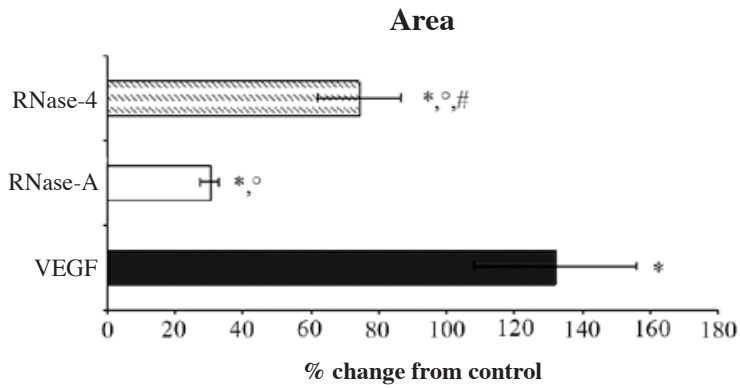

C

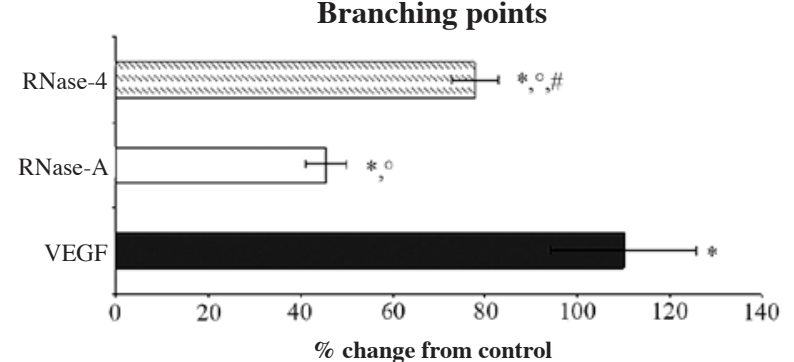

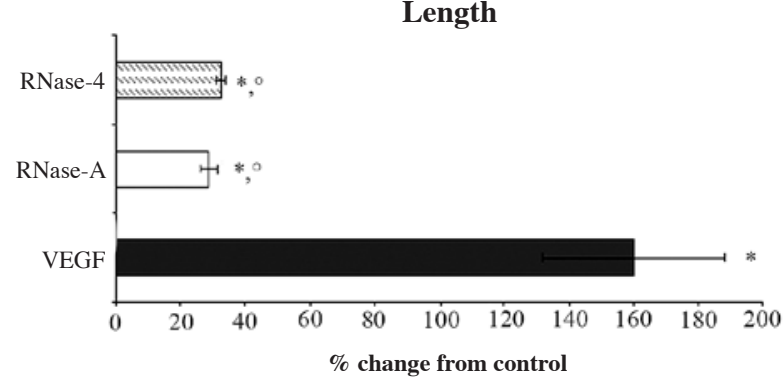

D

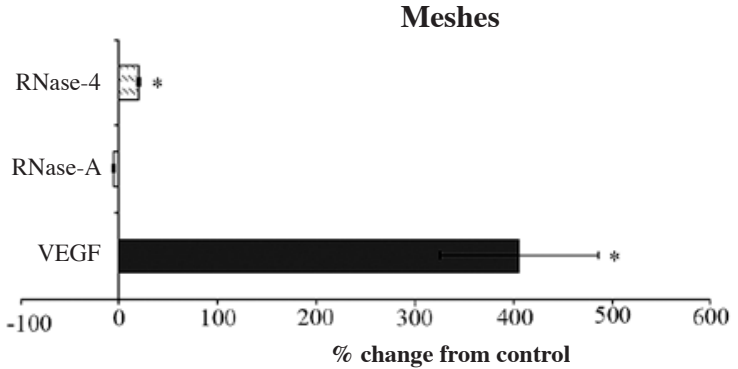

Figure 6. Quantitative analysis of the effect of peptides on dimensional (A, percent area covered; B, total length per field) and topological (C, number of branching points per field; D, number of meshes per field) parameters of HUVEC capillary-like mesh. Bars are the mean \pm SEM of four separate experiments ( ${ }^{*} \mathrm{p}<0.05$ with respect to controls; ${ }^{\circ} \mathrm{p}<0.05$ with respect to $\mathrm{bFGF}$ treatment; ${ }^{*} \mathrm{p}<0.05$ with respect to RNase-A treatment).

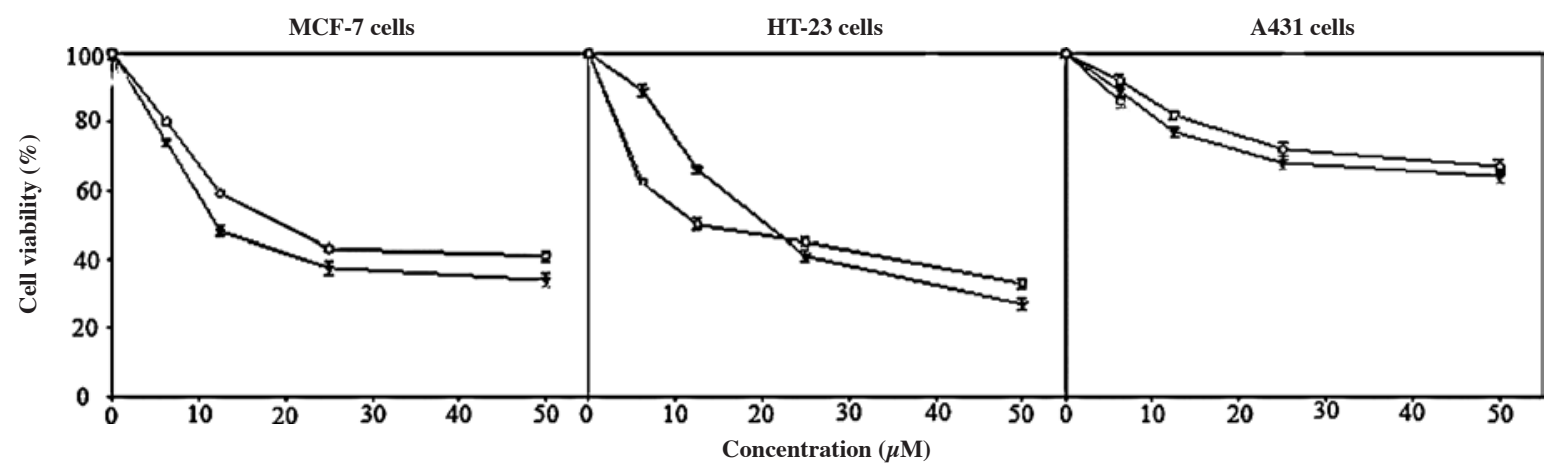

Figure 7. Cytotoxicity of RNase-A ( $\mathbf{v})$ and RNase-4 (O) determined after $72 \mathrm{~h}$ of treatment with MTT. Data are expressed as the percentage of absorbance (490 nm wavelength) with respect to the controls (" $\mathrm{p}<0.05$ with respect to controls).

good conformational stability and resistance to proteolytic degradation favor ribonuclease cytotoxicity. Our proteins were stabilized by four disulfide bridges, and the presence of an N-terminal pyroglutamic residue prevented the degradation of RNase-4.

The capacity to enter target cells is probably the limiting step for cytotoxicity (16). There are no data regarding specific ribonuclease receptors, and the process of nuclear translocation of these proteins is largely unknown. However, cell interactions may be favored by chemical protein characteristics. The observation that ribonucleases were more toxic for tumor cells than healthy ones (3) is probably due to the presence on tumor cell membranes of negatively charged macromolecules such as proteoglycans and polynucleic acids, which favor interactions with positively charged, basic proteins. It has been demonstrated that the variation from negative to positive charge makes ribonucleases more cytotoxic (17), suggesting that basicity may be necessary for this property. The proteins examined here, RNase- 4 and RNase-A, were basic, with an isoelectric point of $>9.5$. This may partly explain their cytotoxicity.

In conclusion, the results demonstrated that the isolation and high-level purification of bovine RNase-4 from milk is possible. In addition, the biological effects of the ribonuclease on normal and tumor cell lines were determined. This study should be regarded as preliminary; a detailed investigation of the mechanisms involved in the biological effects of RNase-4 is ongoing in our laboratory.

\section{Acknowledgements}

The authors are indebted to Dr Diego Guidolin, Department of Human Anatomy and Physiology, University of Padova, for help with the angiogenic assays, and to Professor Christine Marzano, Department of Pharmaceutical Sciences, University of Padova, for help with the cytotoxicity assays. 


\section{References}

1. Rosenberg HF and Domachowske JB: Eosinophils, eosinophil ribonucleases and their role in host defense against respiratory virus pathogens. J Leukoc Biol 70: 691-698, 2001.

2. Kim JS, Soucek J, Matousek J and Raines RT: Structural basis for the biological activities of bovine seminal ribonuclease. $\mathrm{J}$ Biol Chem 270: 10525-10530, 1995.

3. Makarov AA and Ilinskaya ON: Cytotoxic ribonucleases: molecular weapons and their targets. FEBS Lett 540: 15-20, 2003.

4. Hofsteenge J, Vicentini A and Zelenko O: Ribonuclease 4, an evolutionarily highly conserved member of the superfamily. Cell Mol Life Sci 54: 804-810, 1998.

5. Zhou HM and Strydom DJ: The amino acid sequence of human ribonuclease 4 , a highly conserved ribonuclease that cleaves specifically on the 3 ' side of uridine. Eur J Biochem 217: 401-410, 1993.

6. Morita T, Sanda A, Takizawa Y, Ohgi K and Irie M: Distribution of a kidney acid-ribonuclease-like enzyme and the other ribonucleases in bovine organs and body fluids. Agric Biol Chem 51: 2751-2761, 1987.

7. Ye XY, Cheng KJ and $\mathrm{Ng} \mathrm{TB}$ : Isolation and characterization of angiogenin- 1 and a novel protein designated lactogenin from bovine milk. Biochem Biophys Res Commun 263: 187-191, 1999.

8. Schwede T, Kopp J, Guex N and Peitsch MC: SWISS-MODEL: an automated protein homology-modeling server. Nucleic Acid Res 31: 3381-3385, 2003.

9. Gill SG and von Hippel PH: Calculation of protein extinction coefficients from amino acid sequence data. Anal Biochem 182: 319-326, 1989.
10. Toumadje A, Alcorn SW and Johnson WC: Extending CD spectra of proteins to $168 \mathrm{~nm}$ improves the analysis for secondary structures. Anal Biochem 200: 321-331, 1992.

11. Jaffe EA, Nachman RL, Becker CG and Minck CR: Culture of human endothelial cells derived from umbilical veins. Identification by morphologic and immunologic criteria. J Clin Invest 52: 2745-2756, 1973.

12. Ribatti D, Guidolin D, Conconi MT, Nico B, Baiguera S, Parnigotto PP, Vacca A and Nussdorfer GG: Ghrelin inhibits FGF-2-mediated angiogenesis in vitro and in vivo. Oncogene 22: 6458-6461, 2003.

13. Alley MC, Scudiero DA, Monks A, et al: Feasibility of drug screening with panels of human tumor cell lines using a microculture tetrazolium assay. Cancer Res 48: 589-601, 1988.

14. Chen CZ and Shapiro R: Site-specific mutagenesis reveals differences in the structural bases for tight binding of RNase inhibitor to angiogenin and RNase A. Proc Natl Acad Sci USA 94: 1761-1766, 1997.

15. Shapiro R, Fett JW, Strydom DJ and Vallee BL: Isolation and characterization of a human colon carcinoma-secreted enzyme with pancreatic ribonuclease-like activity. Biochemistry 25: 7255-7264, 1986.

16. Leland PA, Schultz LW, Byung-Moon K and Raines T: Ribonuclease A variants with potent cytotoxic activity. Proc Natl Acad Sci USA 95: 10407-10412, 1998.

17. Ilinskaya ON, Dreyer F, Mitkevich VA, Shaw KL, Pace CN and Makarov AA: Changing the net charge from negative to positive makes ribonuclease Sa cytotoxic. Prot Sci 11: 2522-2525, 2002. 